\title{
A Comparison of Oral Health Status in Active-, Occasional- and Non- Smoker Patients Versus Students
}

\author{
Benedek (Bukhari) Csilla¹, Kovács Mónika1, Pop M¹, Balog Anita² \\ 1 Department of Conservative Dentistry and Periodontology, Faculty of Dental Medicine, University of Medicine and Pharmacy, Tîrgu Mureș, Romania \\ 2 Dentist, S.C. Ka-Dent Stomatologie S.R.L., Tîrgu Mureș, Romania
}

\begin{abstract}
Objective: The aim of this case-control study was to assess the smoker and non-smoker patients' oral health status versus students. Methods: The study was based on a clinical examination of 210 young adults (118 women, 92 men) aged between 22-32 years. 105 of these were students in the $5^{\text {th }}$ and $6^{\text {th }}$ grade of the Faculty of Dentistry in Tîrgu Mureș and the control group was represented by patients. Patients and students were classified into three groups: non-smokers, occasional- and active smokers. The clinical examination evaluated the dental caries, fillings, extractions, crowns, root remnants and dental plaque. DMF-S index scores were calculated, and with its help the index of treatment need, dental care index and intensity of caries were determined.

Results: The dental treatment need index, DMF-S index and intensity of caries showed increased values in patients. Root remnants ( $p$ $<0.0001)$, decay $(p=0.0473)$ and dental plaque $(p=0.0363)$ were much higher in the group of active smoker students as in the non-smoker students. Among active smoker patients the incidence of dental calculus $(p=0.0005)$, of root remnants $(p=0.0022)$ and of fillings ( $p=0.0441)$ showed a higher value than in the non-smokers.

Conclusions: This study showed that compared with non-student patients, in dental students, a better oral hygiene was coupled with healthier teeth and periodontal. Poor oral hygiene together with smoking seems to worsen the oral health status.
\end{abstract}

Keywords: oral health status, DMF-S index, intensity of dental caries, tobacco smoking

Received: 20 December 2012

\section{Introduction}

WHO experts have strongly emphasized the damage of teeth and dental health in the last 6-7 decades as a result of harmful practices in people`s lifestyle [1].

Dental caries remains a major public health problem even in the most developed countries affecting $60-90 \%$ of the schoolchildren and the vast majority of adults $[2,3]$. In the developing countries the decay component of the DMF-T index is high among children, whereas in adults the missing component is preeminent [4].

Currently it was registered an increasing trend in DMF$T$ and DMF-S indices which shows an average value in developing countries such as Romania. Romania is in full epidemic of dental caries: $68.8 \%$ of the investigated have cavities [1,5].

The carious lesion shows a fast evolution in young adolescents endangering the pulp, while among elder people its evolution is slower, that extends more on the surface and less in depth. This is the reason why adolescents require special attention of dental practitioners and frequent monitoring of their oral health.

The prevalence of dental caries can decline with changes in lifestyle, better oral hygiene habits. Dental medical students are taught about the importance of the maintenance

Correspondence to: Csilla Benedek

E-mail: benedekc@yahoo.de of a high quality oral hygiene. Patients can easily acquire the information how to maintain proper oral hygiene by preventive programs, brochures, through mass-media or from the dental practitioners. We were curious to know how these two groups could put into practice the obtained information.

The purpose of this study was to evaluate and compare the oral health status of final year students $\left(5^{\text {th }}\right.$ and $6^{\text {th }}$ year) of the Faculty of Dentistry from Tîrgu Mureș to that of patients according special attention to the fact if they are smokers or non-smokers.

\section{Material and method}

Two hundred and ten young adults aged between 22-32 years were clinically examined, 118 of which were women and 92 men. One hundred and five of these were students in the $5^{\text {th }}$ and $6^{\text {th }}$ grade of the Faculty of Dentistry in Tîrgu Mureș and the other half was the control group represented by patients who presented themselves to the regular monitoring or treatment at a dental office from Tîrgu Mureș. From this survey were excluded individuals that were not matching age criteria, those with systemic illnesses or under treatment for chronic diseases and pregnant patients. Study subjects were divided into 3 groups: 1 . non-smokers ( $\mathrm{n}=142$ : 71 students and 71 patients), 2. occasional smokers group ( $\mathrm{n}=18: 9$ students and 9 patients), 3. active smokers ( $n=50: 25$ students and 25 patients). 


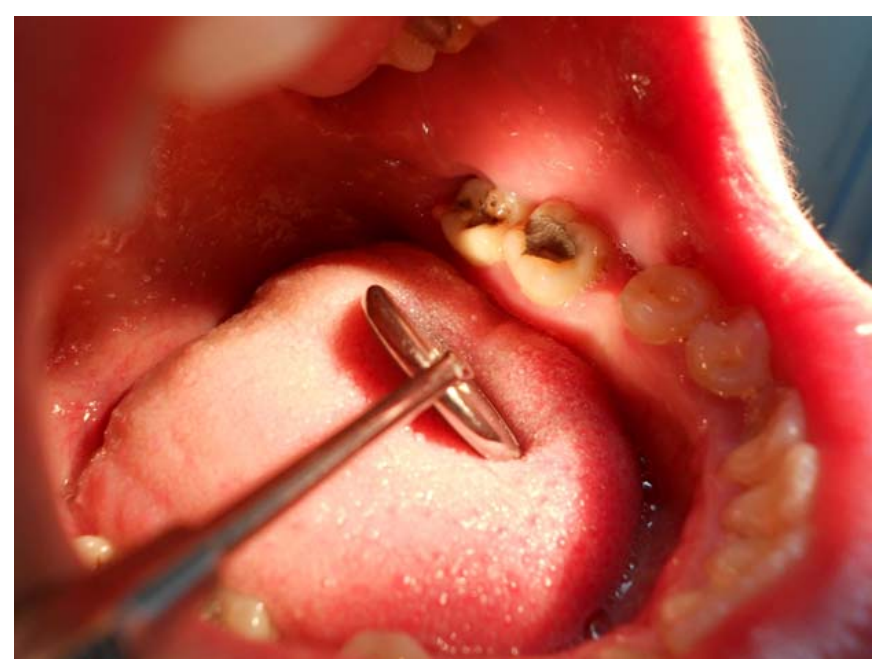

Fig. 1. DMF-S index components on the lower arch of an active smoker patient (own casuistry).

Clinical data on oral health status were collected according to World Health Organization criteria [6]. Clinical examinations were undertaken to record dental caries, fillings, tooth extractions, root remnants, crowns and dental plaque under natural daylight in- and outdoor setting, using dental probe and mirror (Figures 1 and 2).

During the clinical examination severe sterilization procedures were followed to prevent infections. Radiography was not used. Clinical examination was performed following the approval with the number 15/17 April 2012 of the Ethics Committee of the University of Medicine and Pharmacy of Tîrgu Mureș. The students and patients were informed and their written consent was obtained.

DMF-S index scores were computed from the obtained data, and with its help the index of treatment need, dental care index and intensity of caries were determined. Dental caries, filling and dental calculus were counted per dental surfaces. Each crown was taken as 3 surfaces, and each root remnant and tooth extraction was counted as 5 dental surfaces.

After the clinical examination the students and the patients were questioned about their smoking habits and oral hygiene.

Data were statistically analyzed in GraphPad (InStat) program using Pearson`s chi-square test, Man-Whitney test and Student $\mathrm{t}$ test with Welch correction.

\section{Results}

Root remnants $(\mathrm{p}<0.0001)$, decay $(\mathrm{p}=0.047, \mathrm{RR}=1.387$, $95 \% \mathrm{CI}=1.076-1.788)$ and dental plaque $(\mathrm{p}=0.036, \mathrm{RR}$ $=1.549,95 \% \mathrm{CI}=1.092-2.197)$ were much higher in the group of active smoker students as in the non-smoker students. Root remnants $(\mathrm{p}<0.0001)$ and caries $(\mathrm{p}=0.009$, $\mathrm{RR}=0.183,95 \% \mathrm{CI}=0.028-1.176)$ were higher among occasional smoker students' group than the non-smokers (Figure 3).

Among active smoker patients the incidence of dental calculus $(\mathrm{p}=0.0005, \mathrm{RR}=1.719,95 \% \mathrm{CI}=1.344-2.198)$,

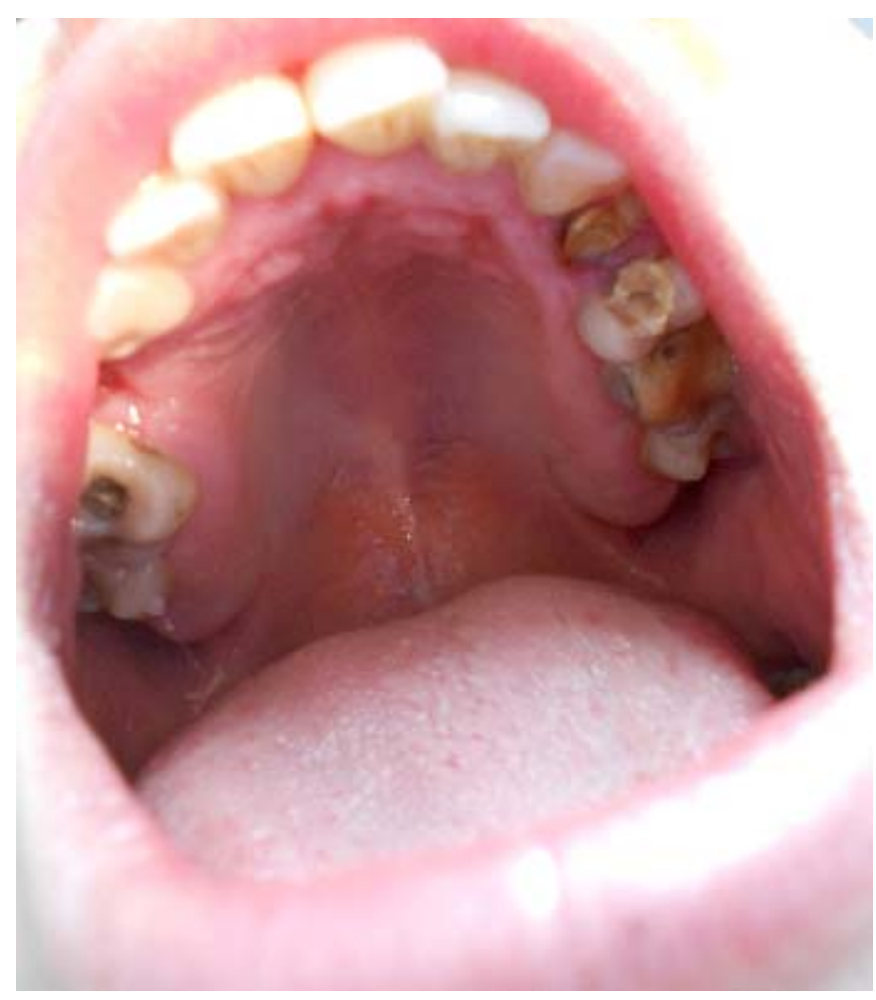

Fig. 2. DMF-S index components on the upper arch of the same active smoker patient (own casuistry).

of root remnants $(\mathrm{p}=0.002, \mathrm{RR}=0.615,95 \% \mathrm{CI}=0.416$ $0.908)$ and of fillings $(\mathrm{p}=0.044, \mathrm{RR}=0.757,95 \% \mathrm{CI}=$ $0.555-1.033)$ showed a higher value than in the nonsmokers. Only the number of root remnants $(\mathrm{p}=0.0003$, $\mathrm{RR}=0.263,95 \% \mathrm{CI}=0.077-0.896)$ was higher in occasional smoker patients than in non-smokers (Figure IV).

Statistically significant differences were found in dental treatment need index $(\mathrm{p}=0.0006,95 \% \mathrm{CI}=11.985-$ 40.164) and in dental care index $(\mathrm{p}=0.0002,95 \% \mathrm{CI}=$ $12.975-30.185)$ in active smokers; in dental care index $(\mathrm{p}=0.0008,95 \% \mathrm{CI}=6.231-31.340)$ and DMF-S in$\operatorname{dex}(\mathrm{p}=0.0004,95 \% \mathrm{CI}=16.236-40.208)$ in occasional smokers and in dental treatment need index $(\mathrm{p}<0.0001$, 95\%CI $=32.435-44.192)$ and dental care index $(\mathrm{p}$ $<0.0001,95 \% \mathrm{CI}=28.070-38.085)$ in non- smokers comparing specific oral health status indices of students versus patients. The dental treatment need index, DMF$S$ index and intensity of caries showed higher values in patients as students, dental care was higher in the group of the students.

In the active smoker group of the patients the majority (48\%) smokes since 6-10 years and most students (52\%) are smoking since $1-5$ years. Most active smoker patients (48\%) are smoking half a package a day and the majority of active smoker students` smokes only 1-5 cigarettes $(32 \%)$ or a whole package per day (28\%) (Figure 5). In case of the occasional smoker group most (by 33.3\%) patients and students smoke 30 cigarettes a week (Figure 6). The active smoker patients intended smoking cessation in a proportion of $52 \%$ and the students in $60 \%$. Among occasional smokers $66.66 \%$ of patients and $33.33 \%$ of 


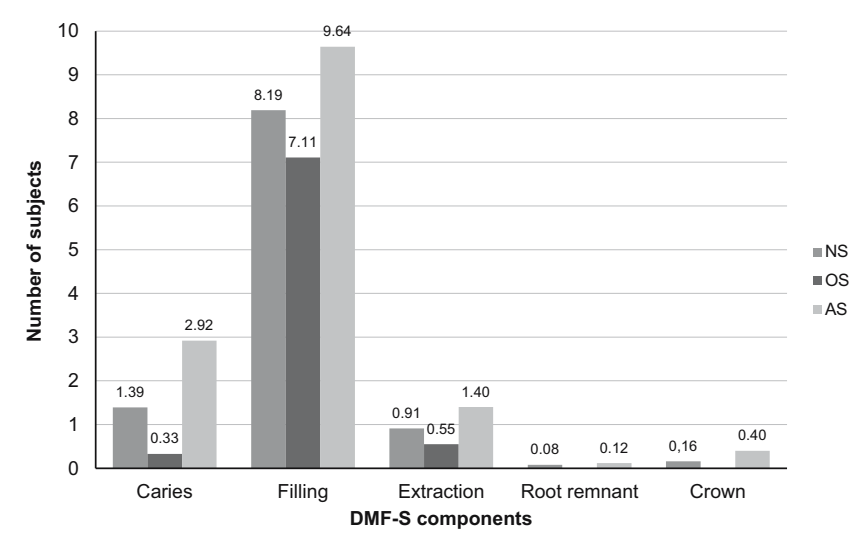

Fig. 3. Comparison of the mean value of five components of the DMF-S index among different student groups (NS: non-smoker group, OS: occasional smoker group, AS: active smoker group).

students have previously quitted smoking for time periods varying between 2 weeks and 1.5-2 years.

In terms of oral hygiene each group of patients presented lower results as students: most students in each group brush their teeth at least 2 times a day, some even 3 times, whereas occasional smoker patients brush their teeth mainly in the morning (55.5\%), active smokers once or 2 times a day and the majority $(61.97 \%)$ of non-smokers conscientiously 2 times a day. Only less than half of the patients are using auxiliary methods, mostly mouthwash and very few (only 8 of 105 patients) use dental floss. On the other hand each student uses mouthwash, dental floss or interdental brush.

Only $35.23 \%$ of the entire group of patients regularly undergoes ultrasonic scaling versus $97.14 \%$ of the students.

\section{Discussion}

Caries affected humans already in prehistoric times [7] and followed a growing trend as civilization evolved. Based on epidemiological studies WHO indicates that in recent decades the dental health has deteriorated due to some harmful habits (increased consumption of refined products, natural food waiver), improper dental hygiene habits and avoidance of dental treatment $[5,8]$.

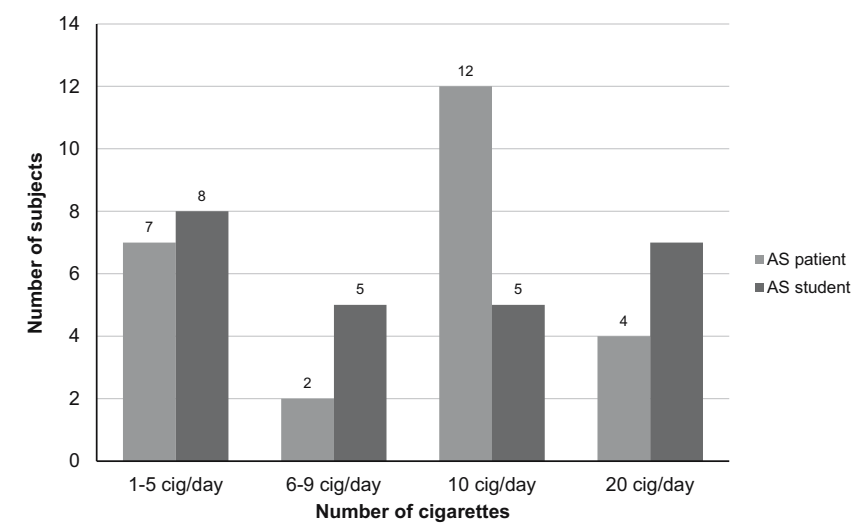

Fig. 5. The density of tobacco consumption among the members of the active smokers group (AS: active smokers, cig: cigarette).

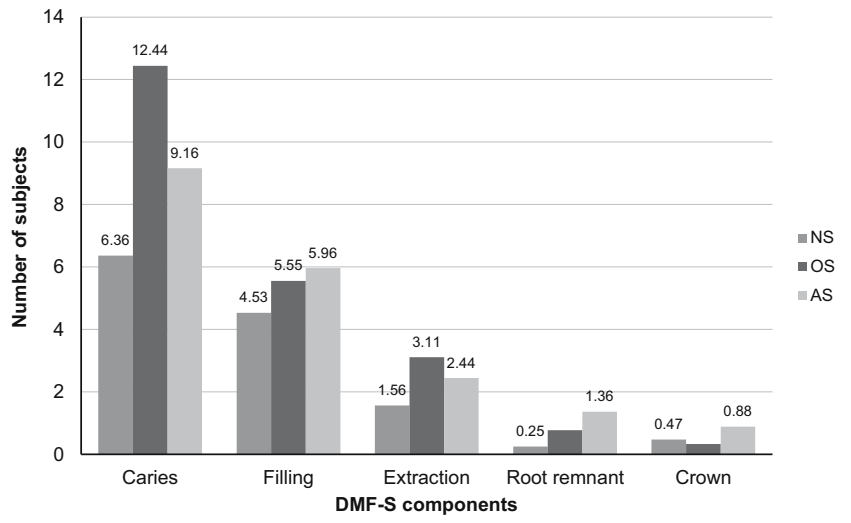

Fig. 4. Comparison of the mean value of five components of the DMF-S index among different patient groups (NS: non-smoker group, OS: occasional smoker group, AS: active smoker group).

This could explain the discrepancy between the students' and the patients ' group in this study. Students learning about the importance of oral hygiene, seeing and treating some difficult cases due to inadequate sanitation, are more aware of this problem, therefore they do not neglect their oral hygiene. As a result, their dental treatment need index is much lower than the dental care index; DMF-S index shows much lower values compared to patients` group.

A previously made cross sectional study in Tîrgu Mureș focused on salivary $\mathrm{pH}$ changes related to DMF-S index. For this reason a saliva sample was collected and oral health status was recorded from hundred school students aged between 7-17 years. This study also showed with the increment in age of students an increased value of DMF-S index and dental caries intensity [9].

A national survey of oral health status made in Turkey on 7833 individuals classified in age groups revealed that only $30.2 \%$ of the 5 -year-old group was caries-free, the prevalence of caries was higher among females than in males and the mean DMF-T increased with the age [3].

A descriptive cross sectional study conducted in SriLanka assessed the prevalence of dental caries among four hundred and ten preschool children aged between 2-5

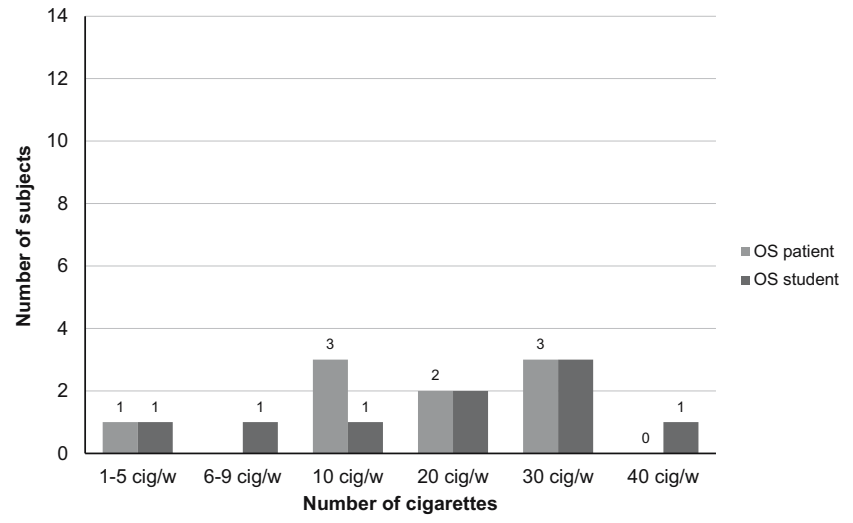

Fig. 6. The density of tobacco consumption among the members of the occasional smokers group (OS: occasional smokers, cig: cigarette, w: week). 
years. It was shown that the prevalence of dental caries gradually increased with age. Decayed tooth were the main contributor for the decayed-extracted-filled score and Care index was only 1.55 [10].

Fortunately, by brushing properly, thoroughly and regularly the appearance of caries and marginal periodontal disease can be prevented [11]. By applying these simple preventative measures teeth can be kept for a long period of time, not to mention that in addition to protecting teeth some auxiliary methods, as the use of a mouthwash play an important role in reducing halitosis and the occurrence of oral cancer $[12,13]$.

This study reveals the differences in oral hygiene habits of the studied groups: most students brush their teeth 2 or even 3 times a day, each of them using auxiliary methods and all received scaling, while many of the patients brush their teeth only once a day, or twice a day in case of the non- smoker group. Less than half of the patients are using auxiliary methods and not all have undergone scaling. Accordingly, this study has shown that oral status of students was better than that of the patients.

Longitudinal studies conducted between 1960-1970 showed that after a perfect professional cleaning, subsequent maintenance of a very good oral hygiene and regular checkups, the occurrence of caries, dental plaque, tartar, gingivitis and marginal periodontitis can successfully be reduced $[14,15]$.

The condition of teeth and gums is influenced by some factors such as nutrition, lifestyle, heredity and quality of hard tooth structure [5,7].

Smoking can lead to the occurrence of cavities as well, by favoring the formation of dental plaque. Similarly, by encouraging bone degradation $[16,17]$ smoking is leading to exposed roots which in turn will offer favorable surfaces for rapid caries development.

This correlation is reflected in this study as well: the active smoker students' and patients` groups shows the greater deposition of tartar and therefore the most inadequate oral status. This is aggravated by an almost non-existent oral hygiene among patients and the carelessness of active smoker patients group towards regular dental checking.

Our body is endowed with a lot of defense mechanisms that can effectively fight against disease. but, unfortunately, by neglecting oral hygiene and with some added risk factors our health can be endangered.

\section{Conclusions}

- In this study most specific oral status indices showed much higher values in active smokers as in non-smokers either in students', either in patients ' group.

- The incidence of tooth decay, of the dental tartar and especially of root remnants was significantly higher in active- and occasional smokers as in non- smokers in case of both study groups: students and patients.

- From the point of view of oral hygiene students presented care and conscientiousness, while smoking patients neglect their oral hygiene measured by the number of daily brushings, by use of auxiliary methods and by the number of ultrasonic scalings.

- The student are using interdental brushes, which is completely unknown for patients.

- Poor oral hygiene together with smoking seems to worsen the oral health status.

- This study showed that compared with non-student patients, in dental students, a better oral hygiene was coupled with healthier teeth and periodontal tissues.

- Tooth decay is a multicausal disease process that occurrence is facilitated by decreasing $\mathrm{pH}$ due to nutrition or vicious habits and hygienic failure.

\section{Acknowledgments}

The authors would like to offer their special thanks to all participants for their cooperation.

\section{References}

1. Ungureanu L. Ancheta epidemiologică în caria dentară, in lliescu A., Gafar M. (eds.): Cariologie și odontoterapie restauratoare, București, Editura Medicală, 2006, 95.

2. Petersen PE. The burden of oral disease: challenges to improving oral health in the $21^{\text {st }}$ century. Bulletin of the World Health Organization. 2005; 83:1-3.

3. Gökalp S, Dogan BG, Tekcicek M, et al. National survey of oral health status of children and adults in Turkey. Community Dental Health. 2010;27:12-17.

4. Brukiene V, Aleksejuniene J, Balciuniene I. Dental treatment needs in Lithuanian adolescents. Stomatologija. 2005;7:11-15.

5. Monea Pop M, Monea A. Caria simplă. Editura University Press, TârguMureș. 2006;19-21,56.

6. World Health Organization. Oral health Surveys: Basic methods, 4th edition, Geneva, 1997

7. Collins M. Good teeth, UK, New Holland Publishers, 2005, 18-20.

8. Bocskay I, Matekovits Gy. A fogszuvasodás kór- és gyógytana (Cariologia), Marosvásárhely, Lyra Kiadó, 2006, 20.

9. Benedek C, Bocskay Ș, Fazakas Z, et al. Studiu cu privire la modificările ph-ului salivar raportat la indicele DMF la un lot de școlari. Revista de Stomatologie - Revista Universității de Vest „Vasile Goldiș” din Arad. 2009;13(2):44-51.

10. Perera PJ, Abeyweera NT, Fernando MP, et al. Prevalence of dental caries among a cohort of preschool children living in Gampaha district, Sri Lanka: A descriptive cross sectional study. BMC Oral Health. 2012;12(1):49.

11. Claydon N. Current concepts in tooth brushing and interdental cleaning. Periodontol 2000. 2008;48:10-23.

12. Scully C, Greenman J. Halitosis (breath odor). Periodontol 2000. 2008;48:66-75.

13. Moran JM. Home-use oral hygiene products: mouthrinses. Periodontol 2000. 2008;48:42-53.

14. Gera I, Vályi P. Oki parodontális terápia, in Gera I. (ed.): Parodontológia, Budapest, Semmelweis Kiadó, 2009, 307.

15. Axelsson P, Nystrom B, Lindhe J. The long-term effect of a plaque control program on tooth mortality, caries and periodontal disease in adults. Results after 30 years of maintenance. J Clin Periodontol. 2004;34:749-757.

16. Gera I, Váry M. A fogágybetegség rizikótényezői és szerepük a fogágybetegség patomechanizmusában, in Gera l. (ed.): Parodontológia, Budapest, Semmelweis Kiadó, 2009, 122.

17. Bergstrom J. Tobacco smoking and risk for periodontal disease. J Clin Periodontol. 2003;30:107-113. 